\title{
ARTÍCULOS
}

\section{MILITANCIA JUVENIL CATÓLICA EN URUGUAY (1966-1973): UN ACERCAMIENTO A SUS ESTRATEGIAS DE INCIDENCIA EN LA UNIVERSIDAD.}

\author{
Lorena García Mourelle \\ Universidade de la República \\ lorenamvd@gmail.com
}

\begin{abstract}
Resumen: En este trabajo se propone una aproximación al estudio de las estrategias que emplearon algunas agrupaciones estudiantiles católicas en Uruguay en pro de incidir dentro del ámbito universitario. A partir de una metodología histórica y cualitativa se identifican las continuidades y rupturas de las formas utilizadas por dichos grupos para alcanzar una mayor influencia en la Universidad de la República, única institución universitaria en la época. Se procura contribuir al estudio del pasado reciente desde un enfoque innovador que coloca la atención en discursos y prácticas desplegadas por sectores juveniles del catolicismo provenientes de la Acción Católica especializada, descuidados por los investigadores nacionales. De este modo, se busca enriquecer la comprensión de procesos locales insertándolos en contextos más amplios a nivel regional latinoamericano y global signados por la Guerra Fría.
\end{abstract}

Palabras clave: Catolicismo, Universidad, Uruguay, militancia, jóvenes, Educación Superior.

Tittle: CATHOLIC YOUTH MILITANCY IN URUGUAY (1966-1973): AN APPROACH TO ITS UNIVERSITY INCIDENCE STRATEGIES.

Abstract: This paper proposes an approach to the study of the strategies used by some Catholic student groups in Uruguay in order to in order to influence within the university. From a historical and qualitative methodology, it identifies the continuities and ruptures of the forms used by these groups to reach a greater influence at Universidad de la República, the only university institution at the time, are identified. It seeks to contribute to the study of the recent past from an innovative approach that places attention on speeches and practices deployed by youth sectors of Catholicism from the specialized Catholic Action neglected by national researchers. In this way, it seeks to enrich the understanding of local processes by inserting them into broader contexts at the Latin American regional level and at a global level marked by the Cold War.

\footnotetext{
1 Este trabajo se enmarca en una investigación más amplia vinculada a mi tesis de maestría en Ciencias Humanas, opción Estudios Latinoamericanos, en la Facultad de Humanidades y Ciencias de la Educación de la Universidad de la República (Montevideo, Uruguay), defendida y aprobada en 2018, y a mi actual proyecto de doctorado en Historia en la misma casa de estudios sobre juventudes católicas en Uruguay en las décadas de 1950 y 1960. Ambos estudios han sido financiados por la Comisión Académica de Posgrado de la Universidad de la República. Agradezco las sugerencias de los réferis anónimos de la revista.
}

Recibido: 11-09-2019

Aceptado: $23-09-2019$

Cómo citar este artículo: GARCÍA MOURELLE, Lorena. Militancia juvenil católica en Uruguay (1966-1973): un acercamiento a sus estrategias de incidencia en la Universidad. Naveg@mérica. Revista electrónica editada por la Asociación Española de Americanistas [en línea]. 2020, n. 24. Disponible en: <http://revistas.um.es/navegamerica>. [Consulta: Fecha de consulta]. ISSN 1989-211X. 
Keywords: Catholicism, University, Uruguay, militancy, youth, Higher Education.

\section{Introducción}

En este trabajo se propone una aproximación al estudio de las estrategias que emplearon algunas agrupaciones estudiantiles católicas en Uruguay en pro de incidir dentro del ámbito universitario. En particular, se concentra en los discursos y las prácticas desplegadas por sectores provenientes de la Acción Católica especializada: la Juventud Universitaria Católica, Parroquia Universitaria y el Movimiento de Cristianos Universitarios. Se toma como período de análisis desde 1966, año de instalación en Montevideo del Secretariado Latinoamericano conjunto del Movimiento Internacional de Estudiantes Católicos de Pax Romana y la Juventud Estudiantil Católica Internacional, y 1973, cuando se iniciaba la última dictadura cívico-militar en el país.

A partir de una metodología histórica y cualitativa se identifican las continuidades y rupturas de las formas utilizadas por dichos grupos para alcanzar una mayor influencia en la Universidad de la República, única institución pública de educación superior en la época. A su vez, se incorporan algunos aportes de la sociología histórica sobre movimientos sociales. Se muestra cómo los jóvenes católicos, en su afán por influir en los ámbitos de decisión de las estructuras universitarias, participaron en el cogobierno, en los gremios estudiantiles y en distintas agrupaciones políticas de izquierda. Se analiza cómo trasladaron a estos terrenos los repertorios de acción que desarrollaban en el interior de sus agrupaciones de apostolado laical.

Sus propuestas los llevaron en ocasiones a entrar en conflicto con la Iglesia, ya que desafiaban normas establecidas por el Vaticano y la jerarquía eclesiástica nacional. Aunque sus posiciones no fueron monolíticas, el giro hacia la izquierda de parte significativa de estos sectores estuvo en el foco de la atención de las autoridades provocando diversas reacciones. Resulta interesante analizar cómo se dieron estos procesos en un país laico como el Uruguay con rasgos distintivos en la región. Algunos autores, como por ejemplo Gerardo Caetano, han señalado cómo tradicionalmente se había caracterizado por un modelo radical de laicidad, donde lo religioso estaba relegado al ámbito privado ${ }^{2}$. No obstante, en los años sesenta se habrían reconfigurado los vínculos entre catolicismo y política, asumiendo características similares a los demás países en América Latina. En ese marco, se dieron experiencias de militancia católica que integraron la fe y la política.

A su vez, se pretende insertar estos cambios en el marco regional y global signado por la Guerra Fría, un período de recrudecimiento de las medidas represivas estatales y de intensificación de las movilizaciones populares impulsadas por los movimientos sociales. Se intenta contribuir a la historia del pasado reciente del Uruguay, en especial, al papel desempeñado por el activismo estudiantil católico en el medio universitario. La historiografía nacional ha desconocido en general los

\footnotetext{
2 CAETANO, Gerardo. Laicidad, ciudadanía y política en el Uruguay contemporáneo: matrices y
} revisiones de una cultura laicista. Revista Cultura y Religión. 2013, n. 1, p. 119. 
aportes del catolicismo en el movimiento estudiantil y la configuración de las izquierdas políticas. Por tanto, se busca enriquecer y ampliar las visiones existentes, incorporando las voces provenientes de sectores juveniles del catolicismo uruguayo, actores y procesos que han sido poco visibilizados y escasamente estudiados, aunque existen investigaciones sobre otros países latinoamericanos.

\section{Acción Católica especializada y compromiso socio-político}

Después de la segunda posguerra, algunos sectores del catolicismo latinoamericano vivieron tiempos de renovación y de tensión que estuvieron fuertemente influidos por distintos fenómenos socio-políticos y culturales de la época. Sobre todo, en enero de 1959 se produjeron dos procesos históricos independientes pero que tuvieron efectos convergentes en América Latina. Por un lado, la convocatoria de un concilio ecuménico por el Papa Juan XXIII que provocó la apertura del catolicismo a un proceso profundo de aggiornamento. Y por otro, el triunfo de la revolución cubana y la entrada de Fidel Castro en La Habana que inauguró un período de casi cuarenta años de luchas sociales y revolucionarias en Latinoamérica. Como explica Michael Löwy, fue a partir de la articulación de estos dos contextos históricos que surgió, a principios de los años sesenta, un movimiento socio-religioso al que define como "cristianismo de la liberación"3. Comprende a un conjunto complejo de reflexiones y prácticas socioreligiosas que cuestionaban la injusticia social y se traducía en el compromiso de los cristianos con la lucha de emancipación de los pobres. Si bien la cuestión de la pobreza había sido tradicionalmente una preocupación fundamental para la Iglesia católica, adquirió en este contexto un enfoque nuevo. Se dejó de considerar al pobre como objeto de ayuda, protección o caridad y se transformó en sujeto histórico, actor de su propia liberación ${ }^{4}$.

De acuerdo a Löwy, estas prácticas se vieron influenciadas por lo que denomina "la afinidad negativa" entre "la ética católica y el capitalismo" capitalismo puede tener raíces en "la identificación ética y religiosa de Cristo con los pobres" y en tradiciones comunitarias en la historia de la Iglesia católica ${ }^{6}$. A su vez, los jóvenes católicos recibieron el influjo del pensamiento católico francés a través de autores como Emmanuel Mounier, Jacques Maritain, Louis-Joseph Lebret, Yves Congar, entre otros, que al ser aplicado a las condiciones latinoamericanas dio como resultado una nueva concepción de la misión de la Iglesia. Esta nueva cultura política-religiosa, al decir de Löwy, auténticamente "latinoamericana", consistió en una selección de las posiciones más avanzadas de los escritos franceses, una creciente incorporación de elementos marxistas y un cambio radical de perspectiva

\footnotetext{
3 LÖWY, Michael. Prefacio: El "comunismo del amor" de Néstor Paz Zamora. En: SUÁREZ, Hugo. Religión y Política en Bolivia, Análisis de la experiencia de Néstor Paz Zamora a partir de tres sociólogos contemporáneos. La Paz: Plural, 1999, pp. 15-17.

${ }^{4}$ LÖWY, Michael. La guerra de los dioses: Religión y política en América Latina. México: Siglo XXI, 1999 , p. 98.

${ }^{5}$ Löwy toma el concepto de "afinidad electiva" de la obra La ética protestante y el espíritu del capitalismo de Max Weber como herramienta metodológica para explicar algunos rasgos del "cristianismo de la liberación". LÖWY, Michael. La guerra... Op. cit., p. 31.

${ }^{6}$ CHÁVEZ, Joaquín. Catholic Action, The Second Vatican Council, and the Emergence of the New Left in El Salvador, (1950- 1975). The Americas. 2014, n. 70, pp. 459-487.
} 
reemplazando el ángulo europeo por el punto de vista de la periferia oprimida del sistema capitalista mundial ${ }^{7}$. Esta emergente cultura católica anticapitalista incidió en los crecientes intercambios entre estudiantes y académicos católicos y marxistas, así como de otras corrientes de izquierda, propiciando una serie de opciones político-religiosas.

En este marco se dio la participación de católicos uruguayos en actividades políticas y gremiales como fue el caso de los jóvenes integrantes de agrupaciones estudiantiles provenientes de la Acción Católica especializada. Se basaban en el modelo teológico-pastoral conocido como "revisión de vida", transmitido por Joseph Cardijn. Este sacerdote belga tomó elementos de las organizaciones de izquierda en el mundo obrero y las adaptó a los ámbitos eclesiales. En especial, se basó en los partidos de cuadros implementados por la izquierda política que priorizaban la calidad de sus miembros a su número y promovía una élite de líderes muy bien formados.

Esta estrategia organizativa fue utilizada primero en la Juventud Obrera Católica (JOC) y más tarde trasladada a otros ámbitos sociales. A nivel rural surgió la Juventud Agraria Católica (JAC), en el sector terciario la Juventud Católica de Medios Independientes (JIC) y en el campo estudiantil: la Juventud Estudiantil Católica (JEC), la Juventud Universitaria Católica (JUC), Parroquia Universitaria y a finales de la década de 1960, el Movimiento de Cristianos Universitarios (MCU). Se organizaban en equipos de base integrados por militantes que, insertos en el medio, promovían la creación de los denominados equipos de influencia. Se buscaba de esta forma extender la organización a otros jóvenes católicos que no conocían la propuesta.

La metodología teológico-pastoral que caracterizó el trabajo de estos grupos consistía en unir la experiencia, en particular la realidad social en la que se movía la persona y su vida religiosa. Constaba de tres pasos: 1) "ver" o analizar un hecho vivido por el grupo; 2) "juzgar" el hecho a la luz del Evangelio y 3) "actuar" en consonancia y como comunidad de creyentes $^{8}$. En lugar de dividirse solo por sexo y edad como era en la Acción Católica General, organizada sobre una estructura territorial piramidal sometida a la vigilancia de los asesores y de las autoridades eclesiásticas, las ramas especializadas se nucleaban de acuerdo al ambiente donde se desarrollaba la tarea pastoral ${ }^{9}$. Se promovía un rol más activo y autónomo de parte de los laicos que implicaba asumir compromisos temporales y su necesaria inserción e intervención en las realidades sociales. A través de la implementación de la "revisión de vida", la fe dejó de estar limitada a la esfera espiritual, impulsando al creyente a salir del ámbito eclesial para incidir y evangelizar sus diversos campos de acción.

\footnotetext{
${ }^{7}$ LÖWY, Michael. La guerra... Op. cit., p. 110.

${ }^{8}$ BIDEGAIN, Ana María. Participación y protagonismo de las mujeres en la historia del catolicismo latinoamericano. Buenos Aires: San Benito, 2009, p. 53.

9 DI STEFANO, Roberto y ZANATTA, Loris. Historia de la Iglesia Argentina, desde la conquista hasta fines del Siglo XX. Buenos Aires: Sudamericana, 2009, p. 385.
} 
Estas prácticas fueron aún más rupturistas para el caso de Uruguay debido a su tradición laica y republicana. Cabe señalar que el territorio uruguayo actual fue tardíamente ocupado y la debilidad institucional que caracterizó a la implantación colonial también afectó al catolicismo. Si bien comparte con México, por ejemplo, una laicización temprana a nivel legal y constitucional, se distancia de éste ya que la religión católica no había sido hegemónica en relación al sistema de representaciones colectivas, como sucedía en la sociedad mexicana ${ }^{10}$. De acuerdo con algunos autores, desde el último cuarto del siglo XIX se vivió un proceso de marginalización institucional de lo religioso del ámbito público y su radicación paulatina en la esfera privada ${ }^{11}$. A partir de entonces se habría producido una progresiva naturalización de un modelo de laicidad radical que fue arraigando como parte de la identidad cultural de su población ${ }^{12}$. Según el sociólogo Néstor Da Costa y otros investigadores, este desplazamiento de lo religioso fuera de la esfera pública creó una especie de religión civil del Estado en donde se sacralizó la política, otorgándole una centralidad para la construcción de lo colectivo ${ }^{13}$. En consecuencia, se relegó lo religioso al espacio privado marginándolo del ámbito institucional y estatal. Sin embargo, en el período estudiado se pueden observar cambios y reconfiguraciones en las relaciones entre catolicismo y política ${ }^{14}$.

En los espacios generados por las ramas especializadas de Acción Católica circularon nuevos discursos críticos influidos por el pensamiento católico europeo. Con un mayor grado de autonomía respecto a las jerarquías eclesiásticas, se convirtieron en ámbitos de discusión y permitieron que los católicos desarrollaran un "proceso de autorreconcimiento"15. El historiador argentino José Zanca advierte que a mediados del siglo XX se produjo el "fin de la cristiandad", un proceso caracterizado por la pérdida de las seguridades que otorgaba el esquema anterior al Concilio Ecuménico Vaticano II (1962-1965), la integración del "otro" y la aceptación de la pluralidad. En ese contexto, aparecieron corrientes reformistas tales como redes de centros pastorales, revistas, asociaciones de laicos e iniciativas locales que en conjunto respondieron a la búsqueda de una presencia más eficaz y significativa

\footnotetext{
10 TORRE, Renée de la. Los símbolos y la disputa por la definición de los límites entre fe y política en México. En: AMEIGEIRAS, Aldo (comp.). Símbolos, rituales religiosos e identidades nacionales: los símbolos religiosos y los procesos de construcción política de identidades en Latinoamérica. Buenos Aires: CLACSO, 2014, pp. 17-38.

11 CAETANO, Gerardo. Laicismo y política en el Uruguay contemporáneo. En: DA COSTA, Néstor (org.). Laicidad en América Latina y Europa. Montevideo: CLAEH, 2006, p. 100.

12 CAETANO, Gerardo. Laicidad,... Op. cit., p. 119.

13 Entre otros, DA COSTA, Néstor. La Laicidad Uruguaya. Archives de Sciences Sociales des Religions. 2009, n. 146, pp. 137-155.

14 Recientemente en la historiografía nacional han aparecido algunas visiones críticas a la caracterización del Uruguay como un modelo de laicidad radical en la región. A partir de renovados marcos teóricos y de nuevas investigaciones empíricas se plantean que estos relatos no alcanzan a explicar de forma convincente los comportamientos asumidos por la Iglesia y los católicos desde la separación constitucional de la Iglesia y el Estado en 1919. Sobre esta discusión historiográfica, vid. por ejemplo, GREISSING, Carolina. El templo de la patria en el Cerrito de la Victoria de Montevideo (Uruguay) y la devoción del Sagrado Corazón de Jesús. Desafíos de la Iglesia Católica separada, 1919-1928. Anuario digital. 2016, n. 28, pp. 119-140.

${ }^{15}$ ZANCA, José. Los intelectuales católicos y el fin de la cristiandad. 1955-1966. Buenos Aires: Fondo de Cultura Económica, 2006, p. 229.
} 
en la vida de sus países ${ }^{16}$. Las agrupaciones estudiantiles católicas analizadas en este trabajo formaban parte de estas redes renovadoras cristianas.

Como se señalaba anteriormente, estas transformaciones dentro del mundo católico convergían con procesos políticos que impactaron en el subcontinente, en particular, la revolución cubana. Para algunos jóvenes católicos estos cambios precipitaban los acontecimientos y exigían una revisión de la misión del laico en el marco de las luchas revolucionarias. Como recordaba Saúl Irureta (pionero fundador de la JUC uruguaya), sentían que "la revolución estaba en la esquina". Buscaron compaginar el deber como cristianos con los cambios que ocurrían en el mundo. Para Irureta, se realizó "un esfuerzo brutal por conciliar el cristianismo con lo que eran las ideologías dominantes, que eran esencialmente marxistas"17. Subrayaba que un tema central durante su etapa como militante jucista en los tempranos sesenta fue el diálogo con el marxismo. Entre los libros de cabecera de estos jóvenes católicos se encontraban las obras de los pensadores franceses Jacques Maritain, Emmanuel Mounier y la revista Esprit, que eran difundidas en el ámbito católico a través de los dominicos franceses residentes en el país. Aunque según Irureta: "lo que más leímos era Emmanuel Mounier, un cristiano que fue uno de los impulsores del diálogo con el marxismo"18.

Como explicaba Ricardo Bernardi, miembro de la JUC, el "descubrimiento" de una nueva forma de Acción Católica los ayudó a valorar el compromiso en el ámbito secular que iba "acompañado paralelamente por un comprender el significado del trabajo gremial". Además de Mounier, subrayaba la influencia del dominico francés Louis-Joseph Lebret, fundador de Economía y Humanismo ${ }^{19}$. Esta doctrina buscaba superar las visiones que restringían al desarrollo a factores económicos, proponiendo una concepción integral entendida como un proceso total de transformación de una sociedad y de sus ambientes con el ser humano como centro $^{20}$.

Según el presbítero Bosco Salvia (asesor eclesiástico de la JUC), cada equipo jucista trabajaba en base a reuniones semanales que se fundamentaban en "la asimilación y puesta en práctica del ver-juzgar-actuar" a través de encuestas y de una observación profunda y lo más exacta posible de la realidad social ${ }^{21}$. Además de propender a formar un "grupo de acción con visión cristiana" se debía tender a formar una comunidad. Ésta se constituía "[...] en la medida que la apertura sincera y evangélica del militante pone en común su reflexión personal, su oración, sus

\footnotetext{
${ }^{16}$ LEVINE, Daniel. Pluralidad, pluralismo y la creación de un vocabulario de derechos. América Latina Hoy. 2005, vol. 41, p. 20.

17 Entrevista a Daisy Solari y Saúl Irureta. Ambos fueron militantes de la Acción Católica General e impulsores de las ramas especializadas en el medio estudiantil en Uruguay. Al casarse en 1965 se alejaron de dichas organizaciones para dedicarse a su familia y sus profesiones, aunque continuaron desarrollando diversas actividades pastorales.

${ }^{18}$ Entrevista a Daisy Solari y Saúl Irureta.

19 Fondo documental conservado por el Espacio Parroquia Universitaria y el Movimiento de Profesionales Católicos (en adelante F.D. EPU-MPC). JUC. Boletín. Uruguay, agosto de 1964.

20 Para más información, vid. PONTUAL, Virgínia. Louis-Joseph Lebret na América Latina: um exitoso laboratório de experiências em planejamento humanita. Rio de Janeiro: Letra Capital, 2016.

${ }^{21}$ F.D. EPU-MPC, JUC. Boletín. Uruguay, agosto de 1964.
} 
vivencias y busca fomentar una verdadera amistad entre los militantes". Para Bernardi, los militantes de la Acción Católica especializada debían reunir una "cuádruple condición": "[...] vivencia profunda de la fe, actitud plena de diálogo, vocación de militancia temporal y deseo de vivencia comunitaria" 22 . Respecto a este último rasgo, se desarrollaron durante los años sesenta distintas experiencias de vida en comunidad en las que participaron algunos estudiantes de las ramas especializadas de Acción Católica. Una de ellas, fue la "Comunidad de La Teja", iniciativa surgida en 1963. Varias parejas de jóvenes católicos pertenecientes a sectores sociales medios y altos decidieron optar por un nuevo estilo de vida y organizarse en un sistema comunitario. Aplicaron el ecumenismo impulsado a partir del Concilio Vaticano II, integrando miembros no creyentes y de otras iglesias cristianas como la metodista ${ }^{23}$. Además de constituir una propuesta que rompía con las prácticas de vida tradicionales pautadas por la Iglesia Católica, fue un espacio de coordinación entre militantes estudiantiles de izquierda que buscaban influir dentro de la federación gremial universitaria.

Como destacaba Salvia, uno de los elementos comunes a estas distintas experiencias laicales fue que contaron con una "metodología" y una estructura que por su carácter internacional favorecía al trabajo y a la formación en la acción del militante de la Acción Católica especializada ${ }^{24}$. Estas organizaciones estaban adheridas a la JEC Internacional y compartían el método de "revisión de vida", contando con el apoyo institucional de este organismo mundial que era reconocido oficialmente por el Vaticano. Además de otorgarles una espiritualidad distintiva fundada en la vocación por la acción militante en los medios seculares, les brindaba formación en aspectos metodológicos y organizativos que resultaron muy importantes al momento de poner en marcha estas formas de apostolado en el país.

\section{Pastoral universitaria y vínculos con la jerarquía eclesiástica}

Estas nuevas prácticas religiosas desplegadas dentro de los movimientos de la Acción Católica especializada coincidían con búsquedas espirituales en un sector del catolicismo que se sintió interpelado por las injusticias sociales que evidenciaban desigualdades cada vez más acentuadas. Los pobres y la pobreza se habían convertido en preocupaciones centrales en los discursos papales de la época, en especial dentro del mundo católico latinoamericano a partir del Concilio Vaticano II. Dicho evento significó una apertura a la "modernidad" y hacia aquellos que no eran católicos, así como también impulsó inquietudes de cambio que se venían desarrollando dentro de comunidades laicales o en institutos educativos. En estos espacios de las ramas especializadas de la Acción Católica, muchos jóvenes se concientizaron de problemáticas que afectaban al país como la pobreza. Estas realidades, que eran comunes a otros casos en el subcontinente americano y a nivel mundial, impactaron fuertemente en sus trayectorias religiosas llevándolos más adelante a radicalizar sus posturas y sus acciones.

\footnotetext{
22 Ibídem.

23 Entrevista a Dorys Zeballos.

${ }^{24}$ F.D. EPU-MPC, JUC. Boletín. Uruguay, agosto de 1964.
} 
Asimismo, los cambios producidos a la interna por las agrupaciones estudiantiles católicas estudiadas impactaron en su relacionamiento con las autoridades eclesiásticas. Como ocurrió en otros casos latinoamericanos, se detectaron ciertos rasgos de anticlericalismo católico que se intensificaron a partir de comienzos de la década de $1960^{25}$. Una de sus expresiones se manifestó con motivo del proyecto de ley de Enseñanza Libre que buscaba crear una universidad católica, designada bajo el nombre de "Universidad libre", impulsada por sectores de la Iglesia Católica (en especial, algunos jesuitas donde se destacó la figura de Carlos Mullin) y autoridades del gobierno nacional (sobre todo el consejero de gobierno Eduardo Víctor Haedo, declarado católico, y el ministro de Salud Pública, Aparicio Méndez) en $1961^{26}$.

Como plantea el historiador Mario Etchechury, dicho proyecto nacía más que como propuesta académica como parte de un proyecto ideológico que apuntaba a desplazar o contrarrestar las tendencias políticas de izquierda presentes en los organismos directivos centrales y de cogobierno de la Universidad de la República (Udelar) que, según la visión de Haedo y de sectores del herrerismo, habían convertido a ese centro de estudios en un "instrumento del marxismo"27. Como explica la historiadora María Eugenia Jung, la Universidad fue señalada por las derechas como un foco de actuación de los "enemigos ideológicos" (marxistas, fuerzas de izquierda de todos los matices) ante las posturas opositoras al gobierno nacional que asumieron algunos actores y sectores universitarios ${ }^{28}$.

La iniciativa de fundar una universidad católica en Uruguay generó tensiones y discusiones tanto a la interna de la Iglesia como a nivel político. Entre aquellos que se opusieron al proyecto se ubicaban los miembros de la Federación Uruguaya de Estudiantes de Acción Católica (FUEAC) que presentaron un informe al cardenal Antonio María Barbieri en nombre de los presidentes de dicha federación y su asesor, el presbítero Omar Ferro, en agosto de 1960. Según Paul Dabezies (sacerdote y asesor eclesiástico del MCU a fines de los sesenta), dicha visión era compartida también por "[...] un grupo considerable de sacerdotes vinculados a ellos,

${ }^{25}$ Se refiere al anticlericalismo surgido de las filas de la misma militancia católica. Para Susana Monreal, este tipo de anticlericalismo adoptó modos diversos, desde versiones "conservadoras" a otras "progresistas". Según esta historiadora uruguaya, la oposición a la creación de una universidad católica en Uruguay en los sesenta puede interpretarse como "una expresión del anticlericalismo cristiano en versión progresista". MONREAL, Susana. El proyecto de Universidad Católica de los sesenta en Uruguay: El debate dentro de la Iglesia. Páginas de Educación [en línea]. 2012, n. 1. [Consulta: 25/03/2017]. Disponible en: <http://www.scielo.edu.uy/pdf/pe/v5n1/v5n1a06.pdf>.

${ }^{26}$ El sacerdote jesuita Carlos Mullin (1914-1985) ingresó a la Compañía de Jesús en 1931 y fue ordenado sacerdote en 1946. En 1950 fue designado ministro de filósofos y profesor de Filosofía en el Colegio Máximo San Miguel en Argentina. En 1954 regresó a Uruguay como maestro de novicios y en 1955 fue designado vice-provincial. Desde su ordenación había mostrado interés en fundar una universidad católica en Uruguay. MONREAL, Susana. El proyecto de... Op. cit.

${ }^{27}$ ETCHECHURY, Mario. Entre el Colegiado y el Vaticano II. Renovación eclesial y política en el catolicismo pre-conciliar. 1958-1962. Monografía de pasaje de curso. Montevideo: Facultad de Humanidades y Ciencias de la Educación, 2004. [Trabajo inédito].

28 JUNG, María Eugenia, La educación superior entre el reclamo localista y la ofensiva derechista. El Movimiento pro Universidad del Norte de Salto (1968-1973). Montevideo: CSIC; Universidad de la República, 2018, p. 14. 
así como militantes de otros movimientos laicales"29. Finalmente, el proyecto de Ley de Enseñanza Libre elaborado por Aparicio Méndez fue presentado a la consideración del Consejo Nacional de Gobierno, liderado por Eduardo Víctor Haedo, pero no tuvo andamiento. Uno de sus principales defensores dentro de la Iglesia, el sacerdote jesuita Carlos Mullin, fue removido de su cargo en Uruguay y trasladado al Paraguay a fines de 1961. Debieron pasar más de dos décadas hasta que se habilitara la fundación de la Universidad Católica del Uruguay Dámaso Antonio Larrañaga en 1984.

Si bien estos episodios demostraron que existían signos de disconformidad en el laicado estudiantil, hasta principios de los años sesenta los vínculos entre las agrupaciones estudiantiles católicas analizadas con la jerarquía eclesiástica uruguaya se habían desarrollado sin demasiadas dificultades. Según Daisy Solari (exintegrante de la FUEAC y fundadora de la JEC Femenina uruguaya), dichas agrupaciones se manejaban con mucha autonomía. Los asesores eran quienes hacían la vinculación con las autoridades eclesiásticas e incluso a veces actuaban como "un colchón que absorbía las tensiones" 30 . El asesor diocesano de la JEC y de la JUC era el presbítero Omar Ferro y el asesor nacional el presbítero Omar Mangado, que además era secretario del cardenal Barbieri y persona de su confianza. Saúl Irureta resaltaba que Mangado había ayudado mucho en las relaciones con el arzobispo porque sabía cómo manejarlo, facilitando así el período de transición de la FUEAC a la Acción Católica especializada en los tempranos sesenta ${ }^{31}$. Sin embargo, a partir de la llegada de monseñor Antonio Corso como administrador apostólico de Montevideo en junio de 1964, crecieron las tensiones con las organizaciones estudiadas. Su administración se caracterizó por la constante invocación al orden, el temor al "relajamiento" de la disciplina y la defensa de la ortodoxia frente a la apertura al mundo moderno ${ }^{32}$.

Como señala Álvaro Martínez: "Mons. Corso se constituirá en la cabeza visible de la resistencia a la aplicación de las reformas del Concilio en la diócesis" 33 . Entre otras medidas, prohibió a los sacerdotes, religiosos y laicos la lectura de determinados autores como Pierre Theilhard de Chardin, revistas como Informationes Catholiques Internationales y prensa periódica que consideraba "tendenciosa" 34 . Como intento de controlar el funcionamiento interno de la JUC, renovó sus autoridades y nombró al presbítero Gonzalo Bueno como asesor en marzo de 1965. Este sacerdote de origen español había llegado a Montevideo en

29 DABEZIES, Paul. No se amolden al tiempo presente. Las relaciones Iglesia-sociedad en los documentos de la Conferencia Episcopal del Uruguay (1965-1985). Montevideo: Obsur; Facultad de Teología del Uruguay, 2009.

30 Entrevista a Daisy Solari y Saúl Irureta.

31 Entrevista a Daisy Solari y Saúl Irureta.

32 Monseñor Antonio Corso (1916-1985) se ordenó de sacerdote en Roma en 1939 y a su vuelta en Uruguay se desempeñó como teniente cura en Rocha, luego como párroco en Rincón del Cerro y en la parroquia del Cordón (Montevideo). El 30 de julio de 1958 fue nombrado obispo auxiliar de Montevideo y más tarde, entre 1964 y 1966 asumió como administrador apostólico sede plena. MARTÍNEZ, Álvaro. La renovación conciliar en Montevideo: Impulsos y resistencias. Montevideo: Obsur, 1990, pp. 31-37.

33 lbídem, p. 28.

34 Ibídem, p. 32. 
1956 enviado por Josemaría Escrivá, fundador de la Prelatura de la Santa Cruz y Opus Dei ${ }^{35}$. Sin embargo, de acuerdo a varios testimonios, su participación no obstaculizó el desarrollo de la JUC ${ }^{36}$.

Las agrupaciones estudiantiles analizadas se convirtieron en espacios de oposición frente a la administración de Corso que mostraba signos conservadores y estaba renuente a la renovación católica que iba ganando espacios en el ámbito eclesial. A medida que la participación social y política de los militantes laicos se tornó más activa y se vincularon en luchas estudiantiles y políticas que aunaban a diferentes grupos ideológicos, se agudizaron las tiranteces con las autoridades diocesanas. A la interna de la Iglesia, la agudización de esta serie de conflictos derivó en el desplazamiento de Corso a la nueva diócesis de Maldonado-Punta del Este en 1966, siendo sustituido en su cargo en la capital del país por monseñor Carlos Parteli. Este último estaba identificado con la corriente renovadora del catolicismo y desde su arzobispado impulsó la aplicación y adaptación de los cambios conciliares promovidos por el Vaticano II y posteriormente por la Conferencia de Medellín en 1968.

Este período se caracterizó también por la generación y fortalecimiento de fuertes lazos entre los grupos juveniles católicos uruguayos con las sedes sudamericanas de apostolado estudiantil por intermedio del Secretariado Latinoamericano (SLA) conjunto del Movimiento Internacional de Estudiantes Católicos (MIEC) de Pax Romana y la Juventud Estudiantil Católica Internacional (JECl). Este organismo funcionó en la ciudad de Montevideo entre 1966 y 1972, constituyéndose en un centro de interacción de ideas, actores e instituciones a nivel regional y global, que revitalizó las prácticas laicales al fortalecer sus vínculos con el exterior. Entre otros instrumentos de formación y comunicación, el SLA contaba con un centro de documentación, que editaba diversas publicaciones como el boletín informativo del Secretariado llamado Spes, el Servicio de Documentación y la revista Víspera. Esta última se editó en Montevideo desde 1967 a 1975 (en total treinta y siete números), constituyendo una fuente fundamental para analizar la renovación del catolicismo latinoamericano en ese período; su editor era el intelectual católico Héctor Borrat y contó con numerosos redactores nacionales y extranjeros. Se distribuía en más de quince países en América Latina, Estados Unidos, Canadá y Bélgica $^{37}$. A través de estos medios se fue profundizando en la conciencia latinoamericanista siendo uno de los rasgos más prominentes en estos sectores del catolicismo. Ana María Bidegain (historiadora uruguaya y exintegrante del MCU) recordaba los vínculos generados con países del Cono Sur y Centroamérica (Argentina, Brasil, Chile, Colombia, El Salvador, etcétera) que "venían con otras experiencias, otros problemas y te abrían otra forma de mirar el mundo"38.

\footnotetext{
35 SANSÓN, Sebastián. Tras 60 años el "fuego interior" del Opus Dei se ha propagado y multiplicado [en línea]. 2016. [Consulta: 08-06-2016]. Disponible en <https://www.revistaecclesia.com/uruguaytras-60-anos-fuego-interior-del-opus-dei-se-ha-propagado-multiplicado/>.

${ }^{36}$ Entrevista a Daisy Solari y Saúl Irureta y Entrevista a Dorys Zeballos.

${ }^{37}$ Víspera, n. ${ }^{\circ} 1,1967-$ n. ${ }^{\circ} 37,1975$.

${ }^{38}$ Entrevista a Ana María Bidegain.
} 
Asimismo, el giro hacia la izquierda que dieron algunos segmentos del catolicismo provenientes de la Acción Católica Especializada necesita además ser inserto en un contexto de confrontación marcado por una nueva etapa de la Guerra Fría latinoamericana donde se recrudecieron los antagonismos. Se apuntaba fundamentalmente a impedir la expansión del "comunismo" en el continente americano, sobre todo a partir de 1961 cuando el gobierno de Fidel Castro se declaró marxista-leninista, incorporándose así a la órbita soviética ${ }^{39}$. Como explica el sociólogo chileno Cristián Parker, el clivaje político-religioso estaba marcado por las ideologías de la Guerra Fría y se conformaba por opciones creyentes de un lado frente a opciones laicistas y no creyentes del otro. De acuerdo a este autor, la Iglesia en América Latina han sido fundamentalmente conservadora del orden moral y, a lo más, propiciadoras de reformas en el plano social ${ }^{40}$. Por ende, era común que se diera una asociación directa entre ser religioso y conservadurismo, ser ateo y ser de izquierda ${ }^{41}$. Por estos motivos, aquellos católicos que proponían diálogos con posturas ideológicas de izquierda o se volcaban a la militancia en organizaciones y partidos de izquierda rompían con el modo tradicional de unir fe y política.

Estas actitudes y prácticas fueron volviéndose cada vez más riesgosas a medida que avanzaba la década de 1960. En esos años se produjo un deterioro incesante de la institucionalidad democrática. Con la llegada a la presidencia de la República de Jorge Pacheco Areco en diciembre de 1967 se intensificaron las medidas represivas del gobierno (clausura de medios de prensa, proscripción de partidos políticos, implantación de Medidas Prontas de Seguridad, encarcelamientos, torturas, asesinatos, etcétera). Este clima de autoritarismo iba en consonancia con el ciclo latinoamericano de golpes de Estado iniciado en 1964 en Brasil y Bolivia que se extendió a lo largo de las dos décadas siguientes. Estos signos de represión se agudizaron hacia los inicios de los setenta con la instalación de la dictadura en el país en junio de 1973.

\section{Estrategias en pro de incidir en la esfera universitaria}

De acuerdo al postulado de insertarse en el medio que caracterizaba a la Acción Católica especializada, los jóvenes estudiantes católicos manifestaron su compromiso militante a través de la intervención en diversas luchas, involucrándose en la actividad gremial y en agrupaciones políticas de izquierda. En el caso de las agrupaciones laicales analizadas, su campo principal de acción fue la Universidad, donde procuraron incidir y plantear vías de transformación. Es importante destacar que la a Universidad de la República, pública y laica, era la institución que detentaba la potestad exclusiva de otorgar títulos habilitantes para el ejercicio de las

\footnotetext{
39 RUIZ, Esther. El Uruguay próspero y su crisis. 1946-1964. En: FREGA, Ana [et al.]. Historia del Uruguay en el siglo XX (1890-2005). Montevideo: Ediciones Banda Oriental, 2008, pp. 123-162.

40 PARKER, Cristián. Religious Pluralism and New Political Identities in Latin America. Latin American Perspectives. 2016, n. 3, p. 6. (Gentileza del autor, versión en español).

${ }^{41}$ Resulta importante señalar que, si bien la vinculación entre conservadurismo y catolicismo fue predominante previo al período analizado, también existieron paralelamente otras posiciones más renovadoras, que dialogaban con actores no cristianos. Entre otros ejemplos, se puede mencionar al grupo conocido como Equipos del Bien Común, fundado en 1947 por Juan Pablo Terra y otros jóvenes de la Federación Universitaria de Estudiantes Católicos, inspirados por Louis-Joseph Lebret y el movimiento Economía y Humanismo.
} 
profesiones en el país. Tras intensas movilizaciones estudiantiles, en 1958 el Parlamento uruguayo había aprobado una nueva ley orgánica que le confería amplia autonomía política, técnica y económica, así como establecía el cogobierno pleno mediante la representación tripartita de los órdenes (docentes, estudiantes y egresados) en sus órganos de conducción. Durante los años sesenta se fue constituyendo en un espacio de disputa donde se generaron intensos debates político-ideológicos, convirtiéndose así en un ámbito de interés público.

Los miembros de la JUC, Parroquia Universitaria y más tarde el MCU, enfocaron su militancia sobre todo en ampliar su influencia dentro de la Federación de Estudiantes Universitarios del Uruguay (FEUU). Dicha organización había sido fundada en 1929 y desde entonces actuaba en forma ininterrumpida. Tenía representación en todos los centros (todas las facultades y escuelas universitarias, así como el Instituto de Profesores "Artigas" que formaba a los docentes de secundaria), siendo así el organismo máximo encargado de definir la política gremial ${ }^{42}$. Desde la implementación de la Ley Orgánica de 1958, los universitarios nucleados en la FEUU tuvieron que elegir delegados para integrar las numerosas comisiones designadas por el Consejo Directivo Central (CDC) de la Universidad.

En su afán por influir en estos ámbitos de decisión, los jóvenes católicos trasladaron y adaptaron al ámbito gremial y político los repertorios de acción que desarrollaban a la interna de sus agrupaciones de apostolado laical. A través de la aplicación de la "revisión de vida" como metodología teológico-pastoral, los jóvenes laicos otorgaron singular relevancia a la praxis en el ambiente donde se desarrollaban. La preparación de los cursos y seminarios de formación, así como los distintos eventos nacionales, regionales e internacionales en los que participaban, constituían verdaderas escuelas de militancia. En dichas instancias aprendían y mejoraban sus habilidades de comunicación y organización que nutrían sus acciones en el medio estudiantil y en el cogobierno universitario. Se preparaban y formaban en oratoria, discutiendo y reflexionando con otros jóvenes e intelectuales católicos. Además, incorporaban metodologías organizativas y adquirían nuevos conocimientos tanto teológico-pastorales, así como de las ciencias sociales y humanas, que les servían de herramientas de análisis para interpretar las realidades nacionales y latinoamericanas.

Con estos repertorios de acción es que se presentaban en las luchas estudiantiles, permitiéndoles también discutir e intercambiar opiniones sobre política universitaria con jóvenes de distintas corrientes ideológico-políticas. Buscaron diversos espacios donde desarrollar estrategias de lucha en el medio estudiantil universitario. Fue así que en los tempranos sesenta varios jóvenes de la JUC y Parroquia Universitaria participaron en la "Comunidad de La Teja". Como se dijo antes, entre otros propósitos implicó un espacio de coordinación entre militantes estudiantiles de izquierda que buscaban influir dentro de la federación gremial universitaria. Estos esfuerzos llevaron a la conformación de una coalición con "izquierdistas independientes" que hacia 1966 logró derrotar a la "alianza marxista"

\footnotetext{
42 MARKARIAN, Vania. El 68 uruguayo. El movimiento estudiantil entre molotovs y música beat. Buenos Aires: Universidad Nacional de Quilmes, 2012, p. 73.
} 
que lideraba entonces a la FEUU ${ }^{43}$. Según el historiador estadounidense Mark Van Aken, bajo la influencia de estos "visionarios católicos de izquierda" el nuevo frente estudiantil preparó un programa "antiimperialista, anticapitalista, vagamente socialista y fervorosamente revolucionario" que obtuvo el control del Consejo Federal de la FEUU 44 .

Entre otros jucistas que participaron en las reuniones semanales de esta comunidad ecuménica se encontraban: Dorys Zeballos y César Aguiar. Este último era dirigente estudiantil del Centro de Estudiantes de la Facultad de Derecho y militaba en la agrupación Acción de Avanzada Universitaria (ADAU). Participó junto a Gustavo Cosse en la "Comunidad de la Teja" entre 1964 y 196745. Por su parte, Zeballos estudiaba profesorado de literatura y desde 1965 participaba en el Centro de Estudiantes del IPA, siendo electa como delegada ante la FEUU junto a otro dirigente de la Unión de Juventudes Comunistas (UJC, sector juvenil del Partido Comunista Uruguayo-PCU). Al igual que otros jóvenes católicos de la época, militaban simultáneamente en actividades pastorales, gremiales y políticas.

En base a la acumulación generada en la "Comunidad de La Teja", algunos jóvenes católicos conformaron el Movimiento de Acción Popular Unitaria (MAPU) en 1966. Esta agrupación política de izquierda surgió como iniciativa de militantes de la JUC uruguaya, entre quienes se encontraba César Aguiar que participó en la redacción del Documento Base ${ }^{46}$. El MAPU tuvo diversas influencias, sobre todo, de la Ação Popular, un movimiento ideológico y político que había surgido en 1962 de una escisión dentro de la JUC en Brasil. Hacia 1966, como ocurrió en otras organizaciones católicas latinoamericanas, Ação Popular se convirtió al marxismoleninismo a través de la versión del maoísmo difundida después de la llamada "revolución cultural" en China.

El giro hacia la izquierda de algunos jucistas uruguayos generó tensiones a la interna de la agrupación ya que varios miembros cuestionaban la fundación de una agrupación política ${ }^{47}$. Hacia 1967 las posiciones ideológico-políticas de dicho grupo se fueron radicalizando y provocaron la escisión de algunos de sus miembros, entre ellos: Aguiar, que se distanció del MAPU "[...] por diferencias con las orientaciones que advertían como dominantes" 48 . Entre julio y agosto de ese año se celebraba en La Habana, Cuba, la conferencia de la Organización Latinoamericana de Solidaridad (OLAS) que tuvo fuerte impacto en el campo de las izquierdas latinoamericanas. En ella se legitimaba la opción por la lucha armada en el continente. En Uruguay, el 12

\footnotetext{
43 VAN AKEN, Mark. Los militantes: Una historia del movimiento estudiantil uruguayo desde sus orígenes hasta 1966. Montevideo: Fondo de Cultura Universitaria, 1990, p. 194.

44 Ibídem.

45 AGUIAR, César. La peripecia fundacional. En: ALONSO, José; BARREIRA, Raquel y ROCHA, Ángel (comps.). Académicos sin Universidad: un testimonio. Los primeros veinte años de CIEDUR. Montevideo, 2017, p. 6. [Trabajo inédito; agradezco a Ángel Rocha haberme permitido consultarlo]. Entre 1972 y 1976 Aguiar fue miembro del equipo de delegados del general Líber Seregni en la presidencia del Frente Amplio. Bajo la dirección de Carlos Filgueira fue parte de la generación fundacional de la carrera de sociología en la Udelar.

${ }^{46}$ AGUIAR, César. La peripecia fundacional. Op. cit., p. 7.

${ }^{47}$ Entrevista a Dorys Zeballos.

${ }^{48}$ AGUIAR, César. La peripecia fundacional. Op. cit., p. 7.
} 
de diciembre de 1967, a la semana de asumir Pacheco la presidencia, se promulgó un decreto que ilegalizaba las agrupaciones políticas que habían apoyado públicamente la plataforma de la OLAS. Entre ellas se encontraba el MAPU. Unos años más tarde, esta agrupación tuvo continuidad en los denominados Grupos de Acción Unificadora (GAU), organización fundada el 19 de abril de 1969 a la que se incorporó un significativo núcleo de militantes sindicales fundamentalmente del sector de la industria textil, liderado por Héctor Rodríguez, así como estudiantes provenientes de la Facultad de Ingeniería.

Estos nuevos ámbitos de acción política impulsados por sectores juveniles católicos se dieron en el marco de reestructuraciones a la interna del apostolado laical. A fines de 1967, un grupo de militantes católicos uruguayos decidieron fusionar la JUC y Parroquia Universitaria para conformar el MCU. Según el "Documento Base" del Equipo coordinador, redactado por Carlos Asuaga y Guzmán Carriquiry, existían fuertes cuestionamientos acerca del sentido, la misión y las estructuras del movimiento ${ }^{49}$. Esta crisis presentaba diversas causas, entre ellas, factores generacionales. Varios jóvenes católicos habían abandonado las agrupaciones de la Acción Católica especializada al culminar su vida estudiantil e ingresaban a una etapa profesional o decidían casarse y constituir sus familias. Además, el surgimiento del MCU estuvo motivado, según Dabezies, por razones internas. Existían fricciones entre ambos colectivos debido a diferencias organizativas. Mientras la JUC estaba constituida por equipos de base que hacían la "revisión de vida" y actuaban desde una perspectiva militante a nivel gremial, Parroquia Universitaria tenía una estructura más abierta, "no necesariamente militante", convocando un número mayor de participantes en actividades más esporádicas. Solían reunirse una vez por mes y en esos encuentros no se hacía estrictamente "revisión de vida" 0 .

Al mismo tiempo, muchos de los jóvenes laicos se retiraron de las ramas especializadas de Acción Católica para incorporarse de lleno a compromisos gremiales y/o políticos. Estos elementos requieren vincularse también con contextos regionales y globales que complejizan la comprensión de estos procesos, sobre todo a partir de finales de los sesenta cuando se precipitaron los acontecimientos. El historiador norteamericano Jeremi Suri plantea cómo en numerosos movimientos de protesta se desarrolló un "lenguaje de disidencia" que permitió expresar la ira como no había ocurrido antes. Muchos manifestantes estudiantiles se movilizaron en torno a una poderosa retórica de crítica social articulada por las élites intelectuales ${ }^{51}$. Estos cambios sacudieron y permearon también en el mundo católico de la época y, en particular, a los jóvenes laicos uruguayos que se estudian en este trabajo.

A pesar de las crisis y transformaciones señaladas, el MCU logró sostener su nueva estructura y continuó sus acciones en el medio universitario durante los difíciles años de la última dictadura (1973-1985), al menos hasta finales de los

49 Fondo documental del Pbro. Paul Dabezies. MCU. Documento base. Campamento 1968. Montevideo, 1968.

50 Entrevista a Paul Dabezies.

51 SURI, Jeremi. Power and Protest: Global Revolution and the Rise of D'etente. Cambridge: Harvard University Press, 2003. 
ochenta. Hacia 1971, el MCU realizaba su campamento anual durante Semana Santa y a partir de las líneas de reflexión que se abrieron en dicha instancia se analizaba, entre otros aspectos, cómo se daba la participación gremial de sus miembros. Reconocían que la atomización del movimiento estudiantil era una de las trabas para asumir su compromiso social y político. Aseguraban:

"Existe un deseo de participación, por la necesidad de sentirse sujeto de la historia. La fe inicialmente puede motivar el compromiso, pero luego al tomarse conciencia de la realidad [...] lleva a un compromiso cada vez más profundo y a que se vea la necesidad de integrarse a un grupo político, como un camino de realizar esa tarea en forma trascendente y eficaz" ${ }^{2}$.

Se referían a algunas dificultades que enfrentaba el MCU cuando quería llevar el "anuncio" a los no cristianos, a lo que denominaban "explicitación de la fe". Entre otros obstáculos mencionaban una formación teológica insuficiente; el lenguaje; condicionamientos del medio (estudiantil, familiar, etcétera). Decían que la "identificación como cristianos y militantes, genera en los otros, una interrogante que nos presenta como signo de contradicción y nos da la ocasión de transmitir nuestra fe". También se cuestionaban cuál debía ser el aporte del MCU al medio: "Debe ser servicio de Iglesia al medio universitario; Debe afrontar una tarea de nucleación (para no ser ghetto)"53. De acuerdo a Dabezies, este campamento de 1971 constituyó una instancia crítica del movimiento donde no se pasó más a la izquierda del Frente Amplio. "Se intentó más pluralidad, por ejemplo, acercar a la CGU [Corriente Gremial Universitaria] pero no se logró" 54 .

Cabe destacar que un número significativo de militantes católicos provenientes de las ramas especializadas de la Acción Católica se abocaron en estos años a la unificación de las izquierdas, esfuerzo que dio como resultado la fundación del Frente Amplio en febrero de 1971. Según documentación interna del MCU, este movimiento proporcionó al nuevo partido dirigentes gremiales y cuadros políticos ${ }^{55}$. En la conformación de la coalición de izquierdas tuvo un papel preponderante el Partido Demócrata Cristiano, que había transitado hacia una progresiva desconfesionalización y un giro hacia la izquierda, iniciando desde 1968 las gestiones para la conformación del Frente Amplio. Entre sus militantes, en especial en la rama universitaria, se encontraban miembros de las agrupaciones analizadas. También hubo jóvenes de la Acción Católica especializada participando en otras vertientes de izquierda, desde el Partido Socialista, el PCU, el Movimiento de Independientes 26 de Marzo, los GAU, etcétera). De acuerdo a Ana María Bidegain, algunos miembros del MCU que militaron gremialmente en la Facultad de Derecho se vincularon al PCU, mientras que dentro de la Facultad de Agronomía actuó un grupo católico ligado al Movimiento de Liberación Nacional-Tupamaros (MLN-T), la principal organización armada en el país ${ }^{56}$.

\footnotetext{
52 F.D. EPU-MPC, MCU. Campamento. Uruguay, 1971.

53 lbídem.

${ }^{54}$ Entrevista a Paul Dabezies

55 F.D. EPU-MPC, MCU. El Movimiento. Uruguay, c. 1972.

56 Entrevista a Ana María Bidegain.
} 
Durante los tempranos setenta, la estructura organizativa del MCU tuvo constantes inconvenientes para su accionar. Expresaban preocupación acerca de la falta de coordinación que existía entre las distintas agrupaciones de católicos universitarios. Si bien muchas veces se relacionaban con la Iglesia a través de las parroquias y de los grupos de pastoral "[...] de hecho su actividad universitaria es autónoma, independiente [...] desconocida por los demás cristianos universitarios". Planteaban la necesidad de una mayor coordinación, sobre todo teniendo en cuenta que el MCU era "[...] el único movimiento organizado de la Iglesia en la Universidad"57. Siguiendo a John McCarthy se puede sostener que en esta etapa los activistas católicos procuraron adaptar e inventar nuevas "formas estructurales de movilización" para que fueran de utilidad para realizar los cambios sociales que se pretendían implementar ${ }^{58}$. En este sentido, establecieron "estructuras de alianza" entre los diversos grupos universitarios de base parroquial que existían en Montevideo, así como participaron activamente en el Coordinador de Movimientos Especializados de la Arquidiócesis ${ }^{59}$.

\section{Palabras finales}

Como se intentó mostrar es este trabajo, en los años sesenta se desarrollaron agrupaciones estudiantiles católica que buscaron mediante diversas estrategias formas de incidir en el ámbito universitario uruguayo. A través de la consulta y sistematización de fuentes documentales aún no investigadas, que se conservan fundamentalmente en el Observatorio del Sur (ONG católica), se buscó visibilizar colectivos juveniles cristianos hasta el momento desatendidos por la historiografía uruguaya. También se realizaron entrevistas semi-estructuradas a actores clave de la época que enriquecieron el análisis de procesos complejos vinculados a la renovación católica de la segunda posguerra fundamentales para comprender mejor los distintos caminos de radicalización religiosa y política transitada por sectores católicos a fines de la década de 1960 en América Latina.

En este período definido por Zanca como "fin de la cristiandad", las agrupaciones de la Acción Católica fueron espacios donde se cuestionó la dimensión política de la fe, llevando a sus miembros a radicalizar sus posturas y, en algunos casos, a tomar la vía de la lucha armada. Estas opciones ideológico-políticas significaron una fuerte ruptura con la tradicional vinculación entre la Iglesia y los sectores conservadores que se dieron en un contexto de confrontación marcado por una nueva etapa de la Guerra Fría latinoamericana. Como sucedía en otros países latinoamericanos, los jóvenes de la Acción Católica especializada asumieron diversos compromisos político-sociales que los llevaron a compartir luchas estudiantiles y sindicales junto a militantes de distintas corrientes ideológicas de izquierda. En particular, los integrantes de la JUC, Parroquia Universitaria y el MCU en Uruguay intervinieron en actividades gremiales y políticas en el medio

\footnotetext{
${ }^{57}$ F.D. EPU-MPC, MCU. Presencia de la Iglesia en la Universidad. Montevideo, c. 1970.

58 McCARTHY, John. Adoptar, adaptar e inventar límites y oportunidades. En: McADAM, Doug; McCARTHY, John y ZALD, Mayer (coords.). Movimientos sociales, perspectivas comparadas: oportunidades políticas, estructuras de movilización y marcos interpretativos culturales. Madrid: Istmo, 1999, pp. 205-220.

59 F.D. EPU-MPC, MCU. El Movimiento. Uruguay, c. 1972.
} 
universitario.

Siguiendo la metodología teológico-pastoral que guiaba estas organizaciones, se insertaron en los ámbitos seculares para desde allí buscar influir y transformar las estructuras de la sociedad. Como se estudió en este trabajo, en el caso uruguayo se dieron algunas particularidades vinculadas a que se trata de un país caracterizado históricamente por su modelo radical de laicidad donde lo religioso estaba relegado al ámbito privado. Sin embargo, en los años analizados se observó una presencia mayor en el espacio público de actores laicos y religiosos. Algunos sectores de la Iglesia Católica mostraron una preocupación por las realidades que afectaban al país y al mundo, asumiendo posturas comprometidas, sobre todo, con los sectores populares. Esta actitud sintonizaba con la renovación que atravesó el catolicismo latinoamericano después de la segunda posguerra, recibiendo el apoyo del Papado y de parte del episcopado. En este contexto, se llevaron a cabo las estrategias del activismo juvenil católico por extender su influencia en la Universidad.

Como se dijo antes, la Universidad de la República era la única institución pública de educación superior en el país y concentraba amplias funciones como la enseñanza, la investigación y la extensión. Desde 1958, año en que se aprobó una nueva ley orgánica, contaba con autonomía política, técnica y económica. También se estableció el cogobierno pleno mediante la representación tripartita de los órdenes (docentes, estudiantes y egresados) en sus órganos de conducción. La Universidad en los años sesenta se había convertido en un espacio de disputa donde se generaron intensos debates político-ideológicos, transformándose en un ámbito de interés público. Por estos motivos, los jóvenes católicos volcaron sus recursos y fuerzas para intentar influir y participar en sus espacios de decisión. En especial, buscaron actuar en el cogobierno universitario y los distintos gremios que integraban la FEUU. A estos espacios trasladaron y adaptaron los repertorios de acción que desarrollaron a la interna de sus agrupaciones de pastoral universitaria.

Desde una metodología histórica y cualitativa, se procuró identificar y analizar las formas de organización y acción escogidas por los grupos universitarios católicos para insertarse en el movimiento estudiantil y los espacios de decisión en la Universidad de la República en Uruguay. Así como también se exploraron las tensiones internas que se desarrollaron en el ámbito eclesial a raíz del involucramiento de los jóvenes laicos en asuntos políticos. De esta manera, se quiso contribuir al estudio del pasado reciente desde un enfoque innovador y casi inexplorado para el caso uruguayo, que coloca la atención en discursos y prácticas desplegadas por agrupaciones católicas descuidadas por los investigadores nacionales. Se piensa que de este modo se puede enriquecer la comprensión de procesos locales sin perder de vista su inserción en contextos más amplios a nivel latinoamericano y global.

\section{Fuentes y bibliografía}

\subsection{Fuentes}

Fondo documental conservado por el Espacio Parroquia Universitaria y el 
Movimiento de Profesionales Católicos (MPC). Montevideo, Uruguay.

Fondo documental del Pbro. Paul Dabezies. Montevideo, Uruguay.

\subsection{Entrevistas (realizadas por la autora)}

Entrevista a Ana María Bidegain.

Fecha y lugar realización de la entrevista: 11 de diciembre de 2015, Montevideo.

Entrevista a Daisy Solari y Saúl Irureta.

Fecha y lugar realización de la entrevista: 16 de diciembre de 2014, Montevideo.

Entrevista a Dorys Zeballos.

Fecha y lugar realización de la entrevista: 26 de mayo de 2016, Santiago de Chile.

Entrevista a Paul Dabezies.

Fecha y lugar realización de la entrevista: 29 de setiembre de 2015, Montevideo.

\subsection{Bibliografía}

AGUIAR, César. La peripecia fundacional. En: ALONSO, José; BARREIRA, Raquel y ROCHA, Ángel (comps.). Académicos sin Universidad: un testimonio. Los primeros veinte años de CIEDUR. Montevideo, 2017, pp. 6-13. [Trabajo inédito].

BIDEGAIN, Ana María. Participación y protagonismo de las mujeres en la historia del catolicismo latinoamericano. Buenos Aires: San Benito, 2009.

CAETANO, Gerardo. Laicismo y política en el Uruguay contemporáneo. En: DA COSTA, Néstor (org.). Laicidad en América Latina y Europa. Montevideo: CLAEH, 2006, pp. 92-123.

CAETANO, Gerardo. Laicidad, ciudadanía y política en el Uruguay contemporáneo: matrices y revisiones de una cultura laicista. Revista Cultura y Religión. 2013, n. 1, pp.116-139.

CHÁVEZ, Joaquín. Catholic Action, The Second Vatican Council, and the Emergence of the New Left in El Salvador, (1950- 1975). The Americas. 2014, n. 70, pp. 459487.

DA COSTA, Néstor. La Laicidad Uruguaya. Archives de Sciences Sociales des Religions. 2009, n. 146, pp. 137-155.

DI STEFANO, Roberto y ZANATTA, Loris. Historia de la Iglesia Argentina, desde la conquista hasta fines del Siglo XX. Buenos Aires: Sudamericana, 2009.

DABEZIES, Paul. No se amolden al tiempo presente. Las relaciones Iglesiasociedad en los documentos de la Conferencia Episcopal del Uruguay (19651985). Montevideo: Obsur; Facultad de Teología del Uruguay, 2009. 
ETCHECHURY, Mario. Entre el Colegiado y el Vaticano II. Renovación eclesial y política en el catolicismo pre-conciliar. 1958-1962. Monografía de pasaje de curso. Montevideo: Facultad de Humanidades y Ciencias de la Educación, 2004. [Trabajo inédito].

GREISSING, Carolina. El templo de la patria en el Cerrito de la Victoria de Montevideo (Uruguay) y la devoción del Sagrado Corazón de Jesús. Desafíos de la Iglesia Católica separada, 1919-1928. Anuario digital. 2016, n. 28, pp. 119140.

JUNG, María Eugenia, La educación superior entre el reclamo localista y la ofensiva derechista. El Movimiento pro Universidad del Norte de Salto (1968-1973). Montevideo: CSIC; Universidad de la República, 2018.

LEVINE, Daniel. Pluralidad, pluralismo y la creación de un vocabulario de derechos. América Latina Hoy. 2005, vol. 41, pp. 17-34.

LÖWY, Michael. Prefacio: El "comunismo del amor" de Néstor Paz Zamora. En: SUÁREZ, Hugo. Religión y Política en Bolivia, Análisis de la experiencia de Néstor Paz Zamora a partir de tres sociólogos contemporáneos. La Paz: Plural, 1999, pp. 15-17.

LÖWY, Michael. La guerra de los dioses: Religión y política en América Latina. México: Siglo XXI, 1999.

MARKARIAN, Vania. El 68 uruguayo. El movimiento estudiantil entre molotovs y música beat. Buenos Aires: Universidad Nacional de Quilmes, 2012.

MARTÍNEZ, Álvaro. La renovación conciliar en Montevideo: Impulsos y resistencias. Montevideo: Obsur, 1990.

McCARTHY, John. Adoptar, adaptar e inventar límites y oportunidades. En: McADAM, Doug; McCARTHY, John y ZALD, Mayer (coords.). Movimientos sociales, perspectivas comparadas: oportunidades políticas, estructuras de movilización y marcos interpretativos culturales. Madrid: Istmo, 1999, pp. 205220.

MONREAL, Susana. El proyecto de Universidad Católica de los sesenta en Uruguay: El debate dentro de la Iglesia. Páginas de Educación [en línea]. 2012, n. 1. [Consulta: 25/03/2017]. Disponible en: <http://www.scielo.edu.uy/pdf/pe/v5n1/v5n1a06.pdf>.

PARKER, Cristián. Religious Pluralism and New Political Identities in Latin America. Latin American Perspectives. 2016, n. 3, pp. 1-16.

PONTUAL, Virgínia. Louis-Joseph Lebret na América Latina: um exitoso laboratório de experiências em planejamento humanita. Rio de Janeiro: Letra Capital, 2016. 
RUIZ, Esther. El Uruguay próspero y su crisis. 1946-1964. En: FREGA, Ana [et al.]. Historia del Uruguay en el siglo XX (1890-2005). Montevideo: Ediciones Banda Oriental, 2008, pp. 123-162.

SANSÓN, Sebastián. Tras 60 años el "fuego interior" del Opus Dei se ha propagado y multiplicado [en línea]. 2016. [Consulta: 08-06-2016]. Disponible en $<$ https://www.revistaecclesia.com/uruguay-tras-60-anos-fuego-interior-del-opusdei-se-ha-propagado-multiplicado/>.

SURI, Jeremi. Power and Protest: Global Revolution and the Rise of D'etente. Cambridge: Harvard University Press, 2003.

TORRE, Renée de la. Los símbolos y la disputa por la definición de los límites entre fe y política en México. En: AMEIGEIRAS, Aldo (comp.). Símbolos, rituales religiosos e identidades nacionales: los símbolos religiosos y los procesos de construcción política de identidades en Latinoamérica. Buenos Aires: CLACSO, 2014, pp. 17-38.

VAN AKEN, Mark. Los militantes: Una historia del movimiento estudiantil uruguayo desde sus orígenes hasta 1966. Montevideo: Fondo de Cultura Universitaria, 1990.

ZANCA, José. Los intelectuales católicos y el fin de la cristiandad. 1955-1966. Buenos Aires: Fondo de Cultura Económica, 2006. 